\title{
Monitoring of Asian houbara bustard Chlamydotis macqueenii populations in Kazakhstan reveals dramatic decline
}

\author{
Christophe Tourenq, Olivier Combreau, Sergey B. Pole, Mark Lawrence, Vladimir S. Ageyev, \\ Alekzey A. Karpov and Frédéric Launay
}

\begin{abstract}
From 1998 to 2002 we monitored changes in the relative abundance of Asian houbara bustard Chlamydotis macqueenii across the greater part of its range in Kazakhstan. The areas most frequented by houbara bustard were the Kyzylkum region, with 35\% of total sightings, and the Betpak-Dala/Muyunkum region with $25 \%$. For all survey areas combined, mean relative abundance ranged from 0.004 to 0.017 individuals seen per $\mathrm{km}$ driven. Density estimates ranged from 0.025 to 0.086 houbara bustard per $\mathrm{km}^{2}$. Between 1999 and 2002 spring relative abundance and density decreased by 65 and $51 \%$ respectively. Likewise, autumn relative abundance
\end{abstract}

decreased by 56\% from 1998 to 2001 and density decreased by 35\% between 1999 and 2001. Kyzylkum had the greatest declines in relative abundance during both spring (78\%) and autumn (61\%). It is highly probable that this observed decline in houbara bustard populations is linked to hunting and poaching pressure, both in Kazakhstan and on the wintering grounds of these Central Asian breeding populations.

Keywords Asian houbara bustard, Chlamydotis macqueenii, hunting, Kazakhstan, population trends.

\section{Introduction}

The Asian houbara bustard Chlamydotis macqueenii (previously Chlamydotis undulata macqueenii but recently reclassified as a full species by Knox et al., 2002) is a desert- and steppe- dwelling bird distributed throughout Central Asia and whose range stretches from Mongolia to the Arabian Peninsula (Del Hoyo et al., 1996). It is categorized as Lower Risk: near threatened on the 2002 IUCN Red List (IUCN, 2002), i.e. it is not facing a high risk of extinction in the wild in the medium-term future. However, a body of evidence indicates that houbara bustard populations are declining rapidly throughout their range due to poaching, excessive hunting and a general impoverishment of their habitat (Collar, 1980; Goriup, 1997; Combreau et al., 2001). To date, there has been no large-scale or long-term census of Asian houbara bustard. Such a census is necessary to understand population trends and to help in the preparation of a long-term

Christophe Tourenq (Corresponding author) Olivier Combreau Mark Lawrence and Frédéric Launay National Avian Research Center, Environmental Research and Wildlife Development Agency, P.O. Box 45553, Abu Dhabi, United Arab Emirates E-mail ctourenq@erwda.gov.ae

Sergey B. Pole, Vladimir S. Ageyev and Alekzey A. Karpov Kazakh Scientific Centre for Quarantine and Zoonosis Diseases, Xaplaskaja 14, Almaty, 480074, Kazakhstan.

Received 29 April 2002. Revision requested 18 September 2002. Accepted 19 June 2003. management strategy for the sustainable use of this species (Cody \& Smallwood, 1996; Primack, 1998), in line with the recommendations of IUCN's Species Survival Commission and the BirdLife International Steppe and Grassland Bird Specialist Group (Goriup, 1997).

Since 1994 the National Avian Research Center (NARC) of the Environmental Research and Wildlife Development Agency of Abu Dhabi, United Arab Emirates, has been building up a network of collaborators within the houbara bustard's range in Asia, with the objectives of studying houbara bustard biology in the field and setting up teams of associates to participate in a population monitoring programme. In 1998 NARC established collaborative links with the Kazakh Central-Asiatic Anti-Plague Research Institute, now renamed the Kazakh Scientific Centre of Quarantine and Zoonosis Diseases (KSCQZD). Created in 1949 in the city of Almaty, the main objective of KSCQZD is the study and prevention of outbreaks of bubonic plague. The objective of this collaboration is to provide data on the long term trends in houbara bustard numbers in Asia.

Kazakhstan is one of the most important breeding grounds for houbara bustard (Gubin, 1992; Goriup, 1997). Populations in western Kazakhstan, from the Caspian to the Aral Sea, migrate through Uzbekistan, Turkmenistan and Iran to winter in Iraq and the northern Arabian Peninsula, whereas populations in eastern Kazakhstan migrate towards Afghanistan and Pakistan through eastern Uzbekistan, Turkmenistan and Iran. The Kyzylkum and Taukum deserts in south and south-east Kazakhstan 
are also important stopover points for houbara bustard migrating through Kazakhstan from more easterly breeding grounds in Mongolia and China, heading towards wintering grounds in Pakistan, Afghanistan and Iran (Combreau et al., 1999a, b, 2001; NARC, unpub. data). Kazakhstan is thus a key country for the houbara bustard, and population trends measured there are a good indicator of the overall conservation status of the species. In this paper we examine trends in houbara bustard populations in Kazakhstan from autumn 1998 to spring 2002, using data collected from the north-eastern Caspian Sea region to the south Balkash Lake region.

\section{Material and methods}

Eighteen KSCQZD Stations were initially chosen to cover the houbara bustard's range in Kazakhstan. In spring 1998 a preliminary survey was conducted to assess the feasibility of large-scale monitoring and the suitability of each station and the area in which it was located. Following this, in autumn 1998, 12 of the 18 stations were selected for inclusion in the full survey. The Stations were located in five geomorphologically distinct regions: I Betpak-Dala/Muyunkum, II North-east Karakum, III Kyzylkum, IV North Caspian, and V South Balkash (Fig. 1).

The surveys were conducted in spring and autumn. Spring surveys monitored the size of the breeding population. In autumn, the birds seen could be either those that bred on site or individuals making stopovers during migration. Spring survey dates were 20 Apr.-8 May 1999, 20 Apr.-5 May 2000, 20 Apr.-20 May 2001 and 15 Apr.-15 May 2002. Autumn survey dates were 20 Sep.5 Oct. 1998, 26 Sep.-10 Oct. 1999, 29 Sep.-22 Oct. 2000 and 17 Sep. -19 Oct. 2001.
As our main objective was to assess the changes in houbara bustard populations over time and across the full distribution range in Kazakhstan, motor vehicle transects were the most practical method to cover the large areas involved (Launay, 1999; Seddon \& van Heezik, 1999). Transect routes were mainly tracks patrolled by KSCQZD scientists undertaking routine monitoring of the level of zoonosis in the rodent populations in Kazakhstan. Each team had three members: a zoologist, an assistant zoologist and a driver. The teams drove a total of c. $1,500 \mathrm{~km}$ each (mean $=1,436 \pm$ SD $521 \mathrm{~km}$ ) at $20 \mathrm{~km} \mathrm{hr}^{-1}$ during a 15-day survey period in spring and autumn. Once a houbara bustard was spotted the location was recorded together with information on behaviour, sex, age and group size. As temperature, rain and wind are parameters that can modify birds' activity, and hence their detectability (Bibby et al., 1993), we discarded any observations that were made during periods of inclement weather.

The significance of trends in relative abundance across areas, years and seasons was assessed by performing nonparametric Friedman's tests (Sokal \& Rohlf, 1997). Density was estimated using distance sampling and the software Distance (Thomas et al., 1998). This method has been validated for the estimation of the density of houbara bustard (Seddon \& van Heezik, 1996, 1999).

\section{Results}

In the surveys 1,237 houbara bustard were counted between autumn 1998 and spring 2002 (Table 1). Thirtyfive percent of sightings were in the Kyzylkum region, $25 \%$ in the Betpak-Dala/Muyunkum region, $19 \%$ in the South Balkash region, $12 \%$ in the North-East Karakum region, and $9 \%$ in the North Caspian region (Table 1 ).
Fig. 1 Areas surveyed for the houbara bustard: I Betpak-Dala/Muyunkum, II North-east Karakum, III Kyzylkum, IV North Caspian, and V South Balkash.

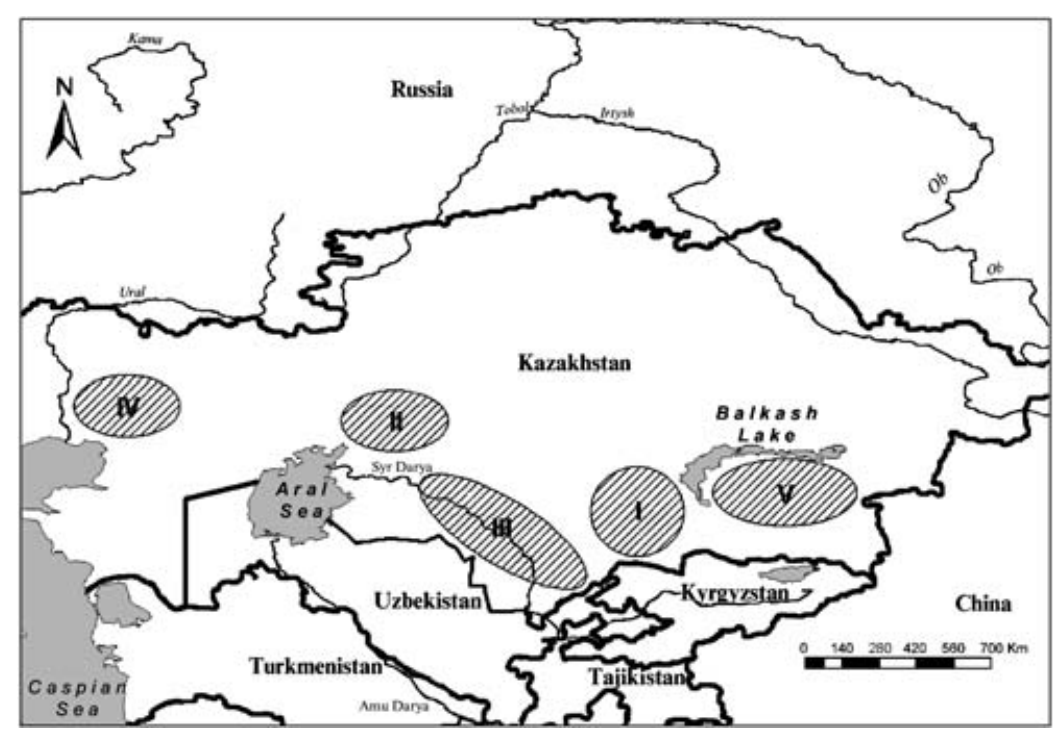


Table 1 Numbers of houbara bustard observed (N) and distance driven (km) from autumn 1998 to spring 2002 from the Stations of the Kazakh Scientific Centre of Quarantine and Zoonosis Diseases (KSCQZD) in five regions of Kazakhstan (see Fig. 1 for locations of numbered regions).

\begin{tabular}{|c|c|c|c|c|c|c|c|c|c|c|c|c|c|c|c|c|}
\hline \multirow{3}{*}{$\begin{array}{l}\text { Regions (I-V) and } \\
\text { KSCQZD Stations } \\
\text { numbered }\end{array}$} & \multirow{2}{*}{\multicolumn{2}{|c|}{$\begin{array}{l}1998 \\
\text { Autumn }\end{array}$}} & \multicolumn{4}{|c|}{1999} & \multicolumn{4}{|c|}{2000} & \multicolumn{4}{|c|}{2001} & \multirow{2}{*}{\multicolumn{2}{|c|}{$\begin{array}{l}2002 \\
\text { Spring }\end{array}$}} \\
\hline & & & \multicolumn{2}{|c|}{ Spring } & \multicolumn{2}{|c|}{ Autumn } & \multicolumn{2}{|c|}{ Spring } & \multicolumn{2}{|c|}{ Autumn } & \multicolumn{2}{|c|}{ Spring } & \multicolumn{2}{|c|}{ Autumn } & & \\
\hline & $\mathrm{N}$ & $\mathrm{km}$ & $\mathrm{N}$ & $\mathrm{km}$ & $\mathrm{N}$ & $\mathrm{km}$ & $\mathrm{N}$ & $\mathrm{km}$ & $\mathrm{N}$ & $\mathrm{km}$ & $\mathrm{N}$ & $\mathrm{km}$ & $\mathrm{N}$ & $\mathrm{km}$ & $\mathrm{N}$ & $\mathrm{km}$ \\
\hline \multicolumn{17}{|c|}{ I Betpak-Dala/Muyunkum } \\
\hline 7 & 3 & 940 & 12 & 1,940 & 27 & 1,930 & 10 & 1,585 & 18 & 1,275 & 9 & 1,530 & 5 & 1,690 & 3 & 1,680 \\
\hline 10 & 32 & 1,140 & 36 & 1,711 & 22 & 1,450 & 27 & 1,581 & 21 & 1,817 & 25 & 2,261 & 31 & 3,711 & 26 & 2,150 \\
\hline \multicolumn{17}{|l|}{ II NE Karakum } \\
\hline 11 & 23 & 1,300 & 19 & 1,300 & 14 & 1,300 & 16 & 1,300 & 14 & 1,300 & 14 & 1,300 & 8 & 1,300 & 8 & 1,626 \\
\hline 14 & 1 & 1,000 & 2 & 1,400 & 8 & 1,500 & 3 & 1,400 & 2 & 1,455 & 4 & 1,400 & 4 & 1,583 & 5 & 2,000 \\
\hline \multicolumn{17}{|l|}{ III Kyzylkum } \\
\hline 9 & 42 & 1,007 & 12 & 1,010 & 65 & 941 & 19 & 822 & 37 & 1,485 & 12 & 1,501 & 29 & 1,059 & 9 & 1,299 \\
\hline 12 & 74 & 1,180 & 42 & 1,200 & 28 & 1,200 & 28 & 1,200 & 6 & 1,200 & 5 & 1,200 & 17 & 1,200 & 9 & 2,075 \\
\hline \multicolumn{17}{|c|}{ IV Northern Caspian } \\
\hline 15 & 4 & 1,000 & 8 & 1,000 & 3 & 1,010 & 3 & 1,050 & 0 & 1,050 & 2 & 1,050 & 0 & 1,050 & 1 & 1,050 \\
\hline 18 & 24 & 1,000 & 9 & 1,123 & 5 & 1,128 & 13 & 1,000 & 7 & 1,051 & 16 & 1,000 & 14 & 1,000 & 9 & 1,306 \\
\hline \multicolumn{17}{|l|}{ V South Balkash } \\
\hline 1 & 8 & 1,025 & 15 & 1,071 & 4 & 1,051 & 18 & 1,090 & 5 & 1,052 & 7 & 1,290 & 7 & 1,335 & 7 & 1,060 \\
\hline 3 & 0 & 1,025 & - & - & 6 & 880 & 5 & 1,492 & 8 & 1,495 & 0 & 1,500 & 4 & 1,459 & 3 & 1,300 \\
\hline 4 & 13 & 1,103 & 8 & 1,250 & 24 & 1,190 & 2 & 1,283 & 2 & 1,487 & 0 & 1,512 & 1 & 1,638 & 2 & 2,986 \\
\hline 6 & 4 & 1,590 & 12 & 1,880 & 14 & 1,700 & 18 & 2,000 & 15 & 2,200 & 4 & 3,062 & 14 & 3,307 & 3 & 3,307 \\
\hline Total & 228 & 13,310 & 175 & 14,885 & 220 & 15,280 & 162 & 15,803 & 135 & 16,867 & 98 & 18,606 & 134 & 20,332 & 85 & 21,839 \\
\hline
\end{tabular}

From autumn 1998 to spring 2002 the relative abundance of houbara bustard (individuals sighted per km driven) varied between years and between seasons (Friedman's test: $\chi_{11,7}=22.81, \mathrm{P}<0.001$; Fig. 2 ). The mean relative abundance in autumn ranged from 0.007 to 0.017 and

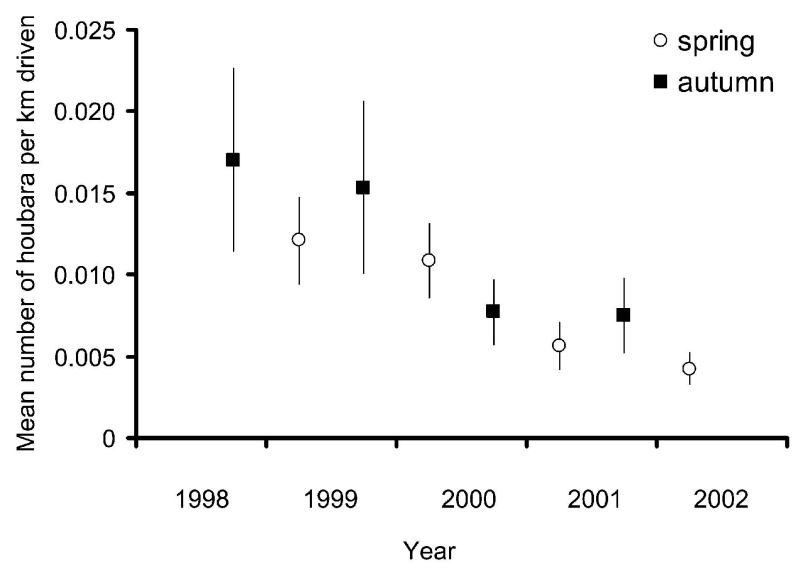

Fig. 2 Annual and seasonal changes in the mean relative abundance of houbara bustard in the five surveyed regions of Kazakhstan combined, from 1998 to 2002 ( $n=12$, bars represent standard errors). in spring from 0.004 to 0.012 individuals per $\mathrm{km}$ driven. From 1999 to 2002, for all regions combined, spring and autumn relative abundances decreased by 65 and $56 \%$ respectively (Fig. 2). The decrease in relative abundance differed between regions and seasons (Fig. 3), with the largest decrease (78\% in spring and $61 \%$ in autumn) observed in the Kyzylkum region. Over the same period spring abundance decreased by $64 \%$ in South Balkash, $54 \%$ in North-East Karakum, $47 \%$ in the North Caspian region and $42 \%$ in Betpak-Dala/Muyunkum. Similarly, from 1998 to 2001 autumn abundance decreased by $60 \%$ in the Betpak-Dala/Muyunkum region, $60 \%$ in North-east Karakum, 51\% in the North Caspian region and 36\% in South Balkash.

Due to inconsistencies in the collection of data, calculation of density estimates was not possible for autumn 1998. Thus, density estimates were only calculated for 1999-2002, and were in the range 0.025-0.086 individuals per $\mathrm{km}^{2}$ (Table 2). Mean densities tended to be greater in autumn (0.063 individuals per $\left.\mathrm{km}^{2}\right)$ than in spring (0.042 individuals per $\mathrm{km}^{2}$ ). From 1999 to 2002 spring density decreased by $51 \%$, and from 1999 to 2001 autumn density decreased by $35 \%$ (Table 2). We could not estimate the densities for each region separately because sample sizes were too small (Buckland et al., 1993). 


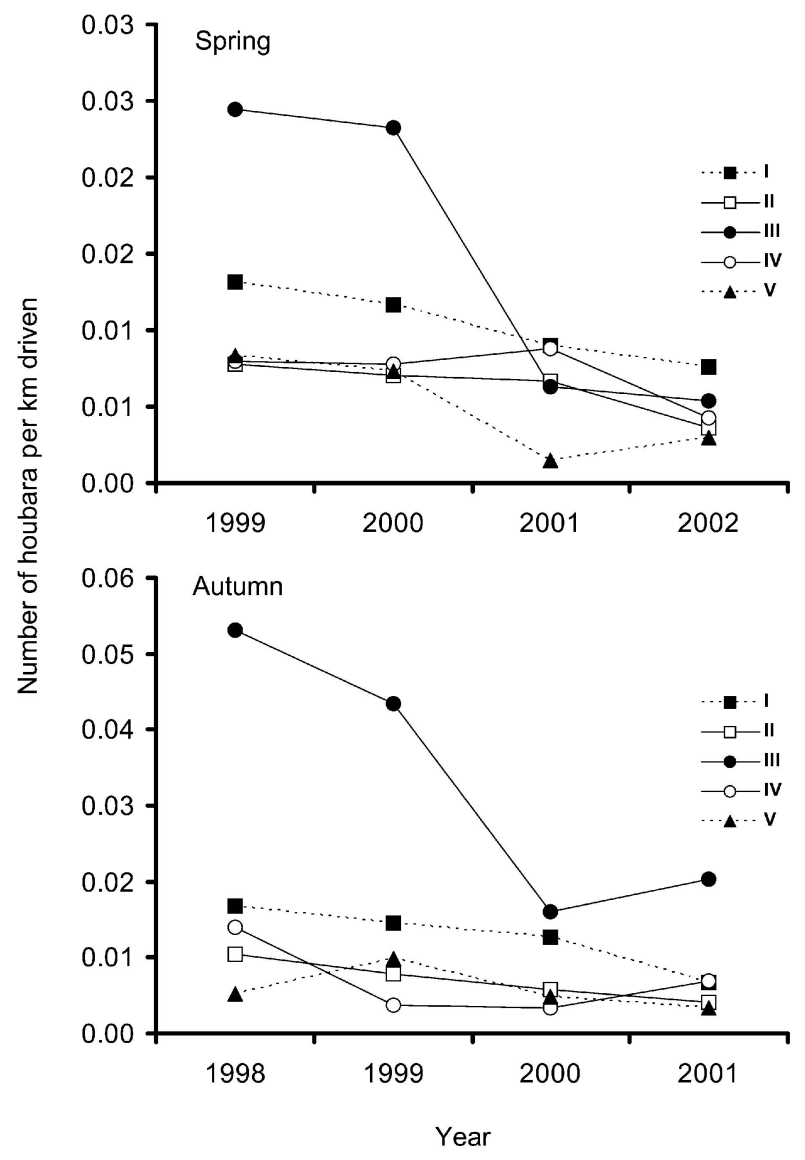

Fig. 3 Changes in relative abundance of houbara bustard in the spring and autumn in the five surveyed regions (see Fig. 1) from 1998 to 2002: I Betpak-Dala/Muyunkum, II North-east Karakum, III Kyzylkum, IV North Caspian, and V South Balkash.

Between 1999 and 2002 the estimated flock size (overall mean $=1.58 \pm S D 1.30$ ) tended to be greater in autumn $($ mean $=1.97)$ than in spring $($ mean $=1.34)$ (Table 2). Birds were found singly or in flocks of 2-19 individuals. Sixty-six percent of sightings were of lone birds and $34 \%$ of flocks of two or more individuals. In spring, birds were found singly or in flocks of $2-11$ individuals, with $74 \%$ of sightings being lone birds and $26 \%$ being of $2-11$ birds. In autumn, flocks ranged in size from $1-19$, with $53 \%$ of sightings being lone birds and 47\% flocks of $2-19$ birds.

\section{Discussion}

Between 1956 and 1979 in the Kyzylkum region Alekseev (1985) recorded relative houbara abundances of 0.008-0.021 individuals per $\mathrm{km}$ in spring and 0.007-0.018 individuals per $\mathrm{km}$ in autumn, values that are similar to our own. Both these and are own estimates of spring relative abundance were lower than values given by Gubin (1992), who calculated figures of 0.031-0.047 houbara bustard per $\mathrm{km}$ in spring 1989. However, a comparison between our figures and those of previous authors needs to be treated with caution. Alekseev (1985) used a combination of car- and foot-transects, and Gubin (1992) used only two car-transects, the rest of the area being surveyed by plane.

Our density estimates of $0.025-0.086$ houbara bustard per $\mathrm{km}^{2}$ are comparable to those estimated by Seddon \& van Heezik (1996) using the same method in Saudi Arabia (0.032-0.097 houbara bustard per $\mathrm{km}^{2}$ ). Spring densities in Kazakhstan (0.042 individuals per $\mathrm{km}^{2}$ ) were comparable to those estimated using the same method in Oman (0.034-0.068 individuals per $\mathrm{km}^{2}$; Lawrence et al., 2001) but lower than in China (0.083 individuals per $\mathrm{km}^{2}$; Combreau et al., 2002).

Estimates of the relative abundance and density of houbara bustard between seasons and regions may be influenced by factors such as behaviour, climate, and the pattern and timing of migration. Differences between spring and autumn may be due to the behaviour of birds on their breeding grounds, which could influence their detectability, and also to the arrival of migrants making stopovers. After the chick rearing period, groups of individuals gather in loose flocks before migration and, in autumn, local and migrating birds may occur at the same location (Launay \& Loughland, 1995; Combreau, 1999; Combreau et al., 1999b). This autumn flocking behaviour can be revealed by the examination of group

Table 2 Number of observations (N), estimates of density (D, with 95\% confidence interval and coefficient of variation, CV) and flock (cluster) size (CS) of houbara bustard in Kazakhstan from the spring of 1999 to the spring of 2002, and the overall averages for density and flock size (with standard deviation, SD) for spring and autumn.

\begin{tabular}{|c|c|c|c|c|c|c|}
\hline \multirow[b]{2}{*}{ Year } & \multicolumn{3}{|c|}{ Spring } & \multicolumn{3}{|c|}{ Autumn } \\
\hline & $\mathrm{N}$ & $D(95 \% C I ; C V)$ & CS $(95 \% C I ; C V)$ & $\mathrm{N}$ & $D(95 \% \mathrm{CI} ; \mathrm{CV})$ & CS $(95 \mathrm{CI} \% ; \mathrm{CV})$ \\
\hline 1999 & 122 & $0.051(0.041-0.064 ; 11.3)$ & $1.434(1.333-1.544 ; 3.7)$ & 109 & $0.086(0.065-0.113 ; 14)$ & $2.018(1.637-2.489 ; 10.6)$ \\
\hline 2000 & 113 & $0.057(0.044-0.073 ; 13)$ & $1.434(1.238-1.661 ; 7.4)$ & 72 & $0.046(0.032-0.066 ; 18.7)$ & $1.875(1.583-2.221 ; 8.5)$ \\
\hline 2001 & 82 & $0.033(0.025-0.042 ; 13)$ & $1.207(1.090-1.337 ; 5.1)$ & 66 & $0.056(0.041-0.078 ; 16.6)$ & $2.030(1.723-2.393 ; 8.2)$ \\
\hline 2002 & 72 & $0.025(0.019-0.033 ; 14.2)$ & $1.181(1.072-1.300 ; 4.8)$ & & & \\
\hline Mean (SD) & & $0.042(0.015)$ & $1.314(0.139)$ & & $0.063(0.020)$ & $1.975(0.086)$ \\
\hline
\end{tabular}


size. Although most of our sightings were of lone birds (66\%; mean flock size of 1.6 individuals), whereas in Saudi Arabia 33\% of sightings were of lone birds and mean flock size was 5.3 (Seddon \& van Heezik, 1996), the flock size in Kazakhstan was greater in autumn than in spring, with groups of two or more birds accounting for $46 \%$ of sightings in autumn and $26 \%$ in spring.

Migration and stopover patterns in birds are largely dependent on weather conditions (Berthold, 1993). In autumn 2000, due to meteorological and technical difficulties, the survey teams began counts 1-2 weeks later (on 10 October) than in other years, and the migration of houbara bustard appeared to have begun earlier, during the middle of September, and intensified after a sharp drop in temperature over the whole of Kazakhstan (extremely low temperatures were recorded, falling below $-7^{\circ} \mathrm{C}$ during the night; S. Pole, unpub. data). Thus, our autumn counts in 2000 may have been underestimates.

Houbara bustard from Kazakhstan exhibit different migration and stopover patterns according to their breeding location (Combreau et al., 1999a). West Kazakhstan populations migrate south towards Iran and Iraq with stopovers in Turkmenistan, whereas houbara bustard from east Kazakhstan migrate south-southeast towards Afghanistan and Baluchistan with stopovers in eastern Iran. Eastern Kazakhstan is also a stopover area for houbara bustard from China and Mongolia migrating towards Pakistan, Afghanistan and Iran (Combreau et al., $1999 b, 2001)$. Studies on the houbara bustard's breeding grounds in China showed a decrease in breeding success during 1999 and 2000 due to predator pressure (Combreau et al., 1999b, 2002). Thus the autumn counts in Kyzylkum, Betpak-Dala/Muyunkum and South Balkash may also be subject to variations in the productivity of Chinese houbara bustard population.

The dramatic decline that we have recorded is most likely a result of increased hunting pressure from falconry and poaching in many areas of the houbara bustard's range in Asia. Houbara bustard were formerly hunted only in their wintering range in the Arabian Peninsula. With the decline of their favourite prey in their own countries, and increased personal resources available from oil wealth, arab falconers from Gulf Cooperation Council countries (Qatar, Kuwait, Saudi Arabia, UAE and Bahrain) started to hunt houbara bustard all over their wintering range from Pakistan in the east to Saudi Arabia in the west. Poor hunting bags in the south of the range over the last 10 years prompted falconers to search for new hunting grounds farther north, in the breeding grounds of the migrant populations in Kazakhstan, China and Mongolia. This trend has been further encouraged by Central Asian countries seeking additional income by inviting hunting parties from the Gulf Cooperation Council area. In Kazakhstan the occurrence of hunting parties is currently increasing, especially in the Kyzylkum and Betpak-Dala/Muyunkum regions, and parties are now hunting as far east as South Balkash (NARC, unpub. data). Houbara bustard are now under threat all along the migration route from their Mongolian, Chinese and east Kazakh breeding grounds through to their wintering grounds. Moreover houbara bustard that reach their wintering grounds in Afghanistan, Pakistan and Iran are heavily poached and transported alive to the Arabian Peninsula for the training of falcons (Bailey et al., 1999; Combreau et al., 2001). It is believed that 4,000-7,000 live houbara bustard enter the United Arab Emirates illegally each year (NARC, unpub. data). Up to the 1990s the number of houbara bustard taken by falconers and poachers was estimated to be 7,000-14,000 individuals per annum for Pakistan alone (Goriup, 1997). Recent estimates suggest that the hunting and poaching pressure on wintering grounds explains $74 \%$ of the observed mortality of adult houbara bustard breeding in Kazakhstan and China (Combreau et al., 2001).

The status of houbara bustard populations and the levels of hunting and poaching pressure are obviously not sustainable and could lead to the extinction of the species. Because of the cultural and traditional importance of houbara bustard and falconry in the Arabian Peninsula, substantial conservation efforts are being undertaken by countries such as the United Arab Emirates and Saudi Arabia. However, to date these efforts remain small in comparison to the scale of falconry activities. In 1996 Saudi Arabia proposed a conservation plan for the houbara bustard under the Convention on Migratory Species, but the agreement is still under negotiation and there is no clear indication that it will be signed in the near future. The decline of houbara bustard numbers is such that the population status in the wild could become beyond recovery before any concerted conservation actions are put in place. Immediate measures need to be taken by falconers, Arabian Gulf and Central Asian countries and international conservation bodies to regulate and decrease the pressure on wild houbara bustard.

\section{Acknowledgements}

The authors are grateful to HH Sheikh Khalifa bin Zayed Al Nahyan, Crown Prince of Abu Dhabi and Chairman of the Environmental Research and Wildlife Development Agency, HH Sheikh Hamdan bin Zayed Al Nahyan, Deputy Chairman of the Board, and to HE Mohammed Al Bowardi, Managing Director, for their support. Our thanks go to Mr. Mohammed Saleh for his help in the field and for his role of coordinator between NARC and KSCQZD. The fieldwork in Kazakhstan would not have been possible without the diligent hard work of all the KSCQZD staff. 


\section{References}

Alekseev, A.F. (1985) The houbara bustard in the north-west Kyzylkum (USSR). Bustard Studies, 3, 87-91.

Bailey, T.A., Silvamose, C.D., Naldo, J., Combreau, O., Launay, F., Wernery, U., Kinne, J., Gough, R. \& Manwell, R. (1999) Health considerations of the rehabilitation of illegally traded houbara bustards Chlamydotis undulata macqueenii in the Middle East. Oryx, 34, 325-334.

Berthold, P. (1993) Bird Migration: A General Survey. Oxford University Press, Oxford, UK.

Bibby, C.J., Burgess, N.D. \& Hill, D.A. (eds) (1993) Bird Census Techniques. Academic Press, London, UK.

Buckland, S.T., Anderson, D.R., Burnham, K.P. \& Laake, J.L. (1993) Distance Sampling-Estimating Abundance of Biological Populations. Chapman and Hall, London, UK.

Cody, M.L. \& Smallwood, J.A. (eds) (1996) Long-term Studies of Vertebrate Communities. Academic Press, San Diego, USA.

Collar, N.J. (1980) The world status of the houbara: a preliminary review. In Symposium Papers of the Small Game Commission of the Conseil International de la Chasse. The Houbara Bustard, Athens, Greece, 1979 (eds C.L. Coles \& N.J. Collar), no pagination. The Game Conservancy, Fordingbridge, UK.

Combreau, O. (1999) Census of houbara bustard in Kazakhstan: evaluation of two different methods. In Counting Houbara Bustard. Technical Publication (eds F. Launay \& T. Bailey) pp. 4-7. National Avian Research Centre, IUCN Species Survival Commission, and BirdLife International, Abu Dhabi, United Arab Emirates.

Combreau, O., Launay, F., Al Bowardi, M. \& Gubin B. (1999a) Outward migration of houbara bustards from two breeding areas in Kazakhstan. Condor, 101, 159-164.

Combreau, O., Gao, X., Saleh, M., Qiao, J., Xu, K., Yao, J., Dai, K. \& Yang, W. (1999b) NARC Expedition to China - April to July 1998. Internal Report. National Avian Research Environmental Research, Wildlife Development Agency, Abu Dhabi, United Arab Emirates.

Combreau, O., Launay, F. \& Lawrence, M. (2001) An assessment of annual mortality rates in adult sized migrant houbara bustards (Chlamydotis [undulata] macqueenii). Animal Conservation, 4, 133-141.

Combreau, O., Qiao, J., Lawrence, M., Gao, X., Yao, J., Yang, W. \& Launay, F. (2002) Breeding success in a Houbara Bustard, Chlamydotis [undulata] macqueenii, population in the eastern fringe of the Jungar basin, People's Republic of China. Ibis, 144, E45-E56.

Del Hoyo, J., Elliot, A. \& Sargatal, J. (1996) Handbook of the Birds of the World. Vol. 3. Lynx Edicions, Barcelona, Spain.

Goriup, P.D. (1997) The world status of the houbara bustard Chlamydotis undulata. Bird Conservation International, 7, 373-397.

Gubin, B.M. (1992) Numbers, distribution and state of protection of the houbara bustard in the south of Kazakhstan. Bustard Studies, 5, 98-103.

IUCN (2002) 2002 IUCN Red List of Threatened Species. IUCN, Gland, Switzerland and Cambridge, UK [http://www.redlist.org, accessed 18 September 2003].

Knox, A.G., Collinson, M., Helbig, A.J., Parkin, D.T. \& Sangster, G. (2002) Taxonomic recommendations for British birds. Ibis, 144, 707-710.
Launay, F. (1999) Conclusions and recommendations. In Counting Houbara Bustard. Technical Publication (eds F. Launay \& T. Bailey), pp. 25-26 National Avian Research Centre, IUCN Species Survival Commission, and BirdLife International, Abu Dhabi, United Arab Emirates.

Launay, F. \& Loughland, R. (1995) Breeding System of Houbara Bustard Chlamydotis undulata macqueenii: Preliminary Observations. Sandgrouse, 35, 14-17.

Lawrence, M., Combreau, O., Saleh, S. \& Mohammed, J. (2001) NARC Survey of Houbara Bustard in the Arabian Oryx Sanctuary, Jiddat Al Harasis, Sultanate of Oman, February-March 2001. Internal Report. National Avian Research Centre, Environmental Research and Wildlife Development Agency, Abu Dhabi, United Arab Emirates.

Primack, R.B. (1998) Essentials of Conservation Biology. Second edition. Sinauer Associates, Sunderland, Massachussets, USA.

Seddon, P.J. \& van Heezik, Y. (1996) Seasonal changes in houbara bustard Chlamydotis undulata macqueenii numbers in Harrat al-Harrah, Saudi Arabia: implications for managing a remnant population. Biological Conservation, 75, 139-146.

Seddon, P.J. \& van Heezik, Y. (1999) Counting houbara bustard in northern Saudi Arabia: an assessment of methods. In Counting Houbara Bustard. Technical Publication (eds F. Launay \& T. Bailey), pp. 18-24. National Avian Research Centre, IUCN Species Survival Commission, and BirdLife International, Abu Dhabi, United Arab Emirates.

Sokal, R.R. \& Rohlf, F.J (1997). Biometry. Third Edition. Freeman, New York, USA.

Thomas, L., Laake, J.L., Derry, J.F., Buckland, S.T., Borchers, D.L., Anderson, D.R., Burnham, K.P., Strindberg, S., Hedley, S.L., Burt, M.L., Marques, F.F.C., Pollard, J.H. \& Fewster, R.M. (1998) Distance 3.5. Release 6. Research Unit for Wildlife Population Assessment, University of St. Andrews, UK [available at http:/ / www.ruwpa.st-and.ac.uk/distance, accessed 29 September 2003].

\section{Biographical sketches}

Christophe Tourenq, Olivier Combreau and Mark Lawrence are respectively Researcher, Director and Conservation Officer at the National Avian Research Center of Abu Dhabi, United Arab Emirates, conducting field studies on the ecology, conservation and sustainable use-planning for the Asian houbara bustard across its whole distribution range.

As Director of the WWF-United Arab Emirates Office and chairman of the IUCN Species Survival Commission Reintroduction Specialist Group, Frédéric Launay is involved in programmes on the ecology, reintroduction and conservation of the houbara bustard.

Sergey B. Pole, Vladimir S. Ageyev and Alekzey A. Karpov are researchers at the Kazakh Scientific Centre for Quarantine and Zoonosis Diseases of Almaty, Kazakhstan, conducting epidemiological surveys and studies on the ecology of steppe-desert rodents as vectors of plague in Kazakhstan. 